\title{
Time and distribution: a model of ape biogeography
}

\author{
J. LehmanN ${ }^{1,2}$, A.H. KorstJens ${ }^{1,3}$ and R.I.M. DunbaR ${ }^{1,4}$ \\ 1 British Academy Centenary Research Project, Institute of Cognitive \& \\ Evolutionary Anthropology, University of Oxford, Oxford OX2 6PN, UK \\ ${ }^{2}$ Human and Life Sciences, Roehampton University, London SW15 4JD, UK \\ ${ }^{3}$ Conservation Sciences, Bournemouth University, Poole BH12 5BB, UK
}

Received 15 July 2008, accepted 15 September 2008

We use data from 20 chimpanzee, bonobo and gorilla study sites to develop an African great ape time budgets model to predict the animals' capacity to survive in a range of habitats across sub-Saharan Africa. The model uses body mass and climatic data to predict the time animals must allocate to key activities (feeding, moving, resting and social interaction), and then uses these to assess the limiting group size that could be sustained in a particular habitat. The model is robust against changes in minimum cut-off values, and predicts the current biogeographic distributions of the two African ape species remarkably well. Predicted group sizes for Pan and Gorilla are close to observed averages. The model also indicates that moving time plays a crucial role for both Pan and Gorilla site presence: i.e. at sites where they are absent it is primarily moving time that is increased as compared to other time budget variables. Finally, the model demonstrates that Pan and Gorilla distributions and group sizes can be accurately modelled by simply modifying the body mass variable, indicating that both share a similar underlying ecological bauplan.

KEY WORDS: great apes, biogeographical distribution, time budgets models, climatic effects.

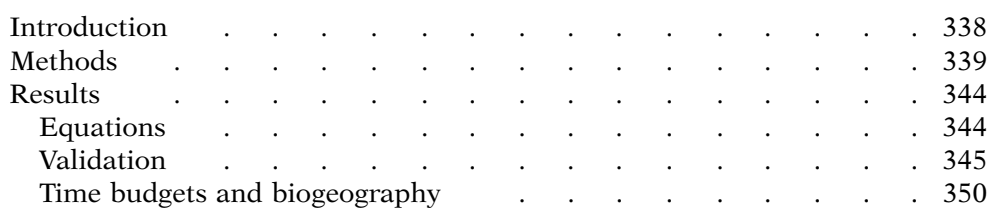

${ }^{4}$ Corresponding author: Robin Dunbar, Institute of Cognitive \& Evolutionary Anthropology, University of Oxford, 64 Banbury Road, Oxford OX2 6PN, UK (E-mail: robin.dunbar@ anthro.ox.ac.uk). 


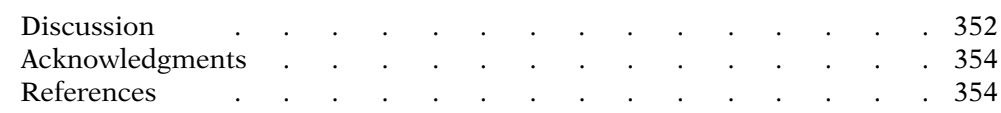

\section{INTRODUCTION}

We have developed a series of taxon-specific models which relate climatic and other environmental variables to the core time budget components (feeding, moving, resting and social interaction) (baboons: DunBAR 1992a, 1992b; spider monkeys: KorstJens et al. 2006; African colobine monkeys: Korstjens \& Dunbar 2007; Pan: Lehmann et al. 2007a; gorillas: Lehmann et al. 2008). These models use climatic variables to predict the amount of time animals have to devote to each time budget component, mediated by physiological mechanisms associated with dietary adaptations, energetic demand and thermoregulation. These models are taxon- and habitat-specific: in other words, they are based on the unique physiological characteristics of a given "ecological species" (i.e. a set of species that share the same dietetic, physiological and life history adaptations) and their response to the climate and environment that characterises a particular site.

The objective of these models is to determine the maximum ecologically tolerable size of group that, under given ecological conditions, a population can maintain as a coherent social unit. A species that cannot live in groups larger than some environmentally-specified minimum group size will not be able to survive in that particular habitat. The models are based on the assumption that, because the amount of daytime is fixed, an animal has to balance its nutritional intake and expenditure while trading off the different time budget components. In addition, within-group competition will lead to feedback consequences for some of the time budget components. In effect, the models are based on the observed relationships between climatic and time budget variables as observed across a large number of populations to determine how much time a virtual ape ought to invest in each time budget component at a specific location and group size. These models differ from the more conventional bivariate logistic models used to predict a taxon's presence/ absence from climatic or other environmental data because they incorporate a middle step in the form of time budgets: this allows us to provide a mechanism to explain why a taxon is present or not at a given site in a way that more conventional analyses cannot do.

These models are surprisingly successful in predicting where a particular species can live on a broad continental scale. Moreover, differences between taxa in the way individual time budget components respond to climatic and environmental variables provide illuminating insights into the constraints that act to prevent a species inhabiting the whole of the continent it lives on. This in turn can explain why species occupy different ecological niches, and hence have geographical ranges that only partially overlap.

Hitherto, these models have focussed explicitly on genus-level analyses (this seemingly being more or less equivalent to an "ecological species"). This 
was done to avoid introducing complications due to between-taxon differences in physiology and life history and so allow the model-building process to focus explicitly on the ecological effects of environmental parameters. In this paper, we take the first steps in trying to build a generic model by focussing on the African great apes. We seek to develop a single model that incorporates both Pan and Gorilla in such a way as to explain the biogeographic and demographic differences between these two genera. More generic models of this kind will help us to understand species differences and similarities in terms of their ecological bauplan as well as in terms of niche separation. Finally, such models have implications for conservation because they allow researchers to investigate exactly how changes in one environmental variable will affect different species.

\section{METHODS}

Data

Behaviour. We used the combined dataset of previously published studies (LEHMANN et al. 2007a, 2008) that give quantitative data on Pan and Gorilla group sizes and structure (group size, party size, demography), time budgets (percentage of time spent feeding, resting, travelling and grooming) and diet (percentage of fruits and leaves in the diet). In total, behavioural data from 20 different study sites were collated. These data were used for finding the time budget equations (see Table 1). Studies in which apes were either provisioned or observed at particular locations only (Bai habitat studies) were excluded from the time budget analysis as these factors are known to bias the data (WRANGHAM 1974).

Climate data. Climate data for the ape study sites were also taken from LeHMANN et al. (2007a, 2008). As in previous studies, we used data from the Willmott \& MatSUURA (2001) weather database for those study sites for which we did not find original climate data. Willmott \& MatsuURa (2001) provide a global dataset of monthly and annual temperature and rainfall in grids of $0.5^{\circ}$ latitude by longitude, based on a combination of the Global Historical Climatology Network (GHCN version 2) and Legates \& Willmotт (1990a, 1990b) weather station records of monthly and annual mean air temperature and total precipitation. For each site for which climate data were required, we calculated average values over those data points in the Willmott \& MatsuURA dataset that fell within a radius of $0.5^{\circ}$ longitude and latitude to the site.

The following climate variables were used in this study: mean annual rainfall in $\mathrm{mm}$ (i.e. annual rainfall averaged across years; $\mathrm{P}_{\mathrm{ann}}$ ), mean annual temperature in ${ }^{\circ} \mathrm{C}\left(\mathrm{T}_{\mathrm{ann}}\right)$, temperature variation between months (calculated as the standard deviation across the 12 monthly average values: $\mathrm{T}_{\mathrm{mo}} \mathrm{SD}$ ), mean monthly rainfall in $\mathrm{mm}$ (averaged across month; $\mathrm{P}_{\mathrm{mo}}$ ), rainfall variation between months (measured as the standard deviation across average values for 12 months: $\mathrm{P}_{\mathrm{mo}} \mathrm{SD}$ ), number of months per year with less than $50 \mathrm{~mm}$ of rainfall $(\mathrm{P}<50)$, number of months per year with less than $100 \mathrm{~mm}$ of rainfall $(\mathrm{P}<100)$ and the plant productivity index $\mathrm{P}>2 \mathrm{~T}$ (the number of months in the year in which rainfall [in $\mathrm{mm}$ ] was more than twice the average monthly temperature (Le Houérou 1984). P > 2T is a reliable index of the growing season in tropical habitats, as it yields a very strong correlation with primary productivity (LE HouéRou 1984), while $\mathrm{P}<50$ and $\mathrm{P}<100$ can be regarded as alternative measures of seasonality. We also included data on the moisture index (annual mean, monthly minimum/maximum and monthly variation) (WillmotT \& Feddema 1992). Previous models of primate socio- 


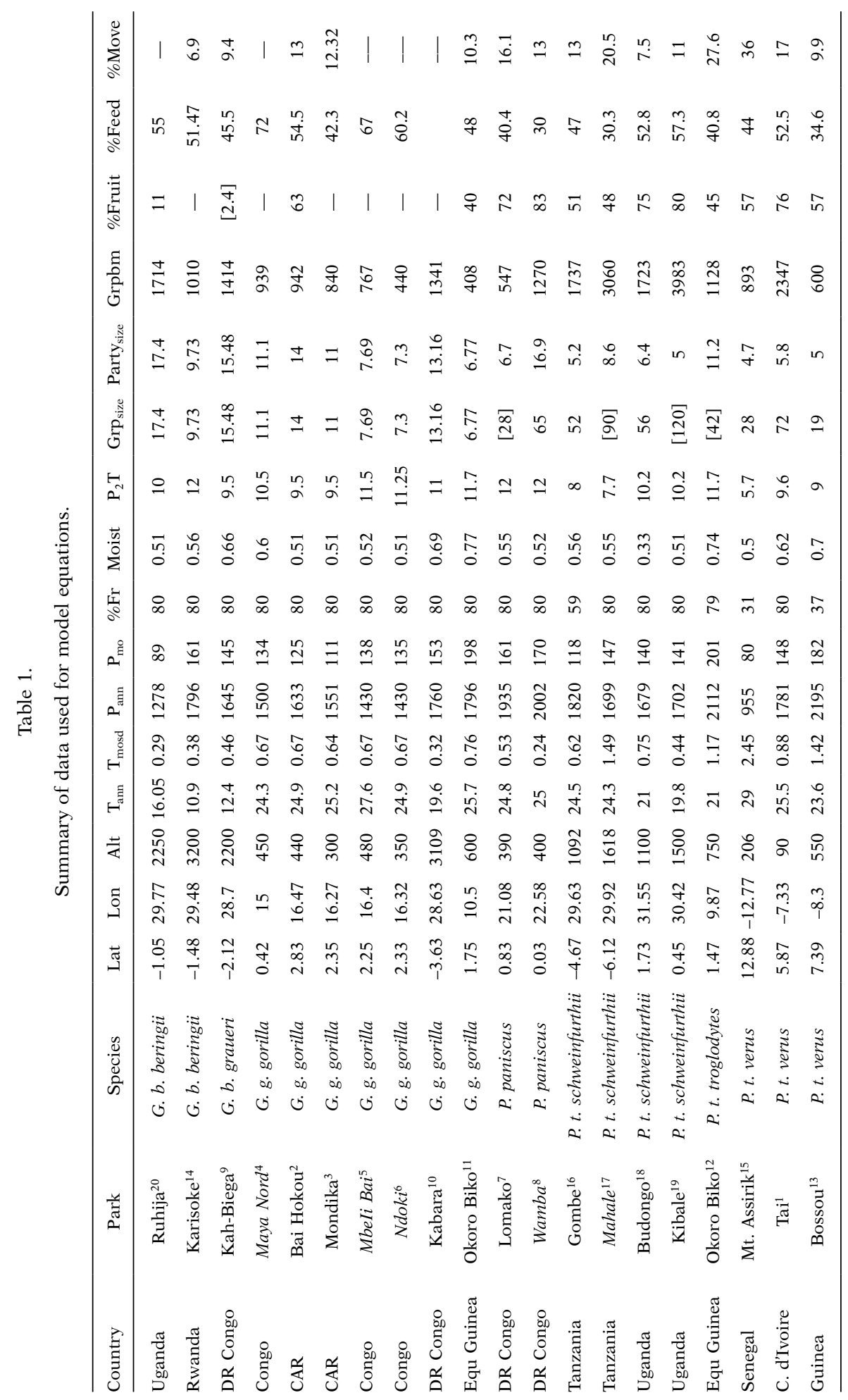




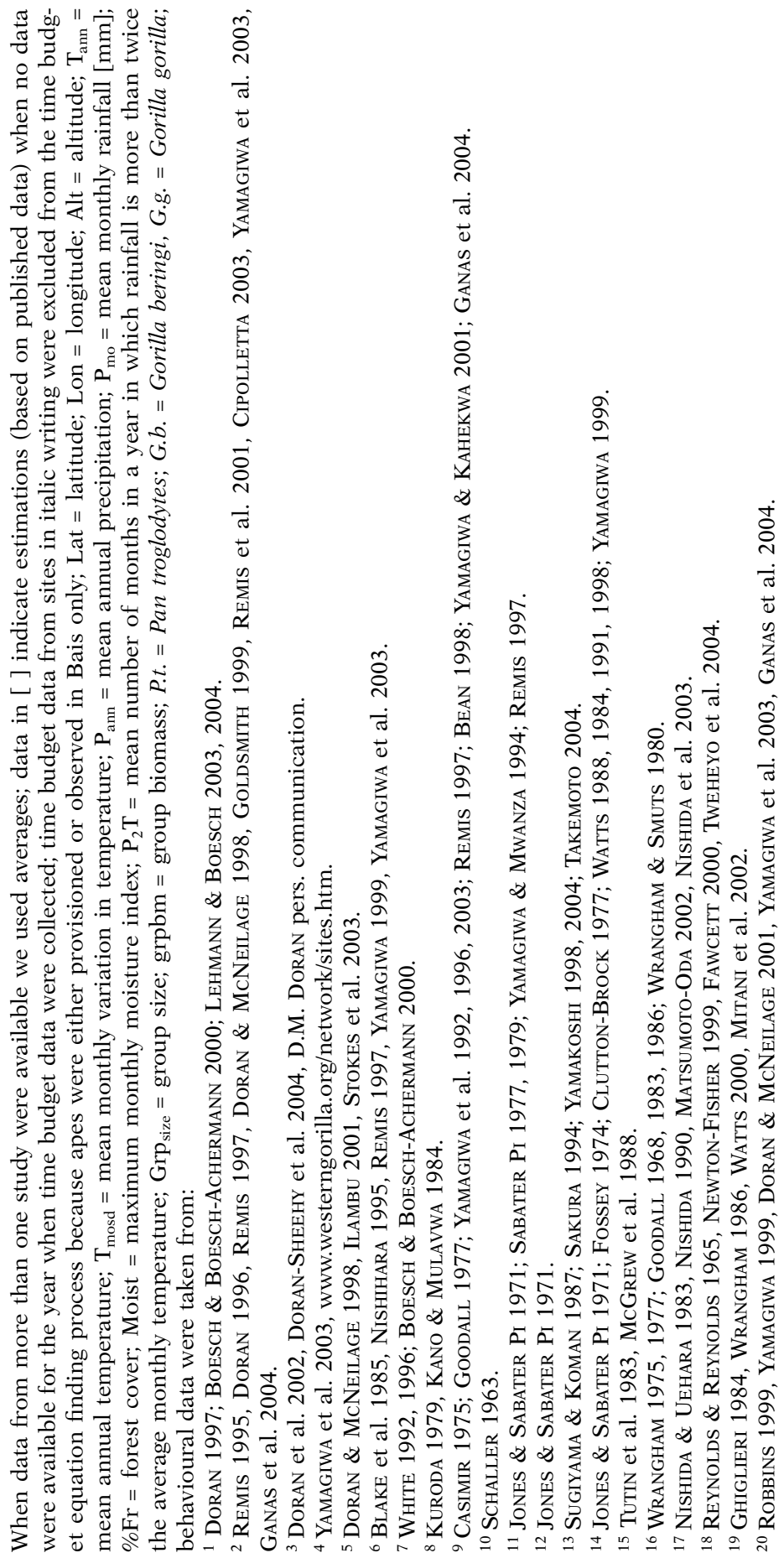


ecology have shown that these variables can be important determinants of time budget (Dunbar 1992a, 1992b; Williamson \& Dunbar 1999; Hill \& Dunbar 2002). In addition, we also used AVHRR satellite data on forest cover from DE FRIES et al. (2000) to determine the percentage of forest cover for each of our sites.

\section{Model components}

Group and party size. Because of the differences in ape social organisation, we draw a distinction between the group (i.e. the relatively stable set of individuals who share a common range area) and the party (i.e. the often unstable set of individuals who feed, rest or travel together at any given moment). In gorillas, groups and parties are usually one and the same, while in Pan, party size is usually significantly smaller than group size (GoOdall 1968, Nishida 1979). Party size has been shown to be primarily driven by ecological conditions, such as food distribution (WRANGHAM 1977, 2000; Wrangham et al. 1992; Chapman et al. 1995; Boesch 1996; Matsumoto-Oda et al. 1998). Average party size for Pan was determined by an equation based on climatic conditions and forest cover (LeHMANN et al. 2007a). Data on group size was available for 32 different populations.

Body mass. Because gorillas and Pan differ substantially in body mass, we included species-typical body masses as well as party biomass as independent variables into the model. Party biomass was calculated on the basis of group composition and known body masses for individual subspecies. Juveniles were assumed to weigh half and infants to weight a quarter of the mean adult body weight.

Diet. Because the major components of ape diets consist of fruits (in the case of Pan) and leaves (in the case of Gorilla), we restricted our model to these two categories and assumed that they are mutually exclusive. Diet composition is assumed to be influenced by ecology/climate as well as by body mass and was usually measured as the percentage of feeding time spent on either fruit or leaves.

Feeding and moving time. We assume that feeding and moving time are independently determined by some combination of climate, diet, body weight, party size and/or group size.

Grooming time. Grooming time is important for group cohesion (and hence their resistance to permanent fission), and was determined by a generic grooming equation because the amount of time that ought to be devoted to grooming in order to prevent groups from breaking up may differ from the actual observed amount of time spent grooming at a particular site by animals living in a group of a particular size, because grooming time might be traded for more urgent activities (see, for example, ALtMANN 1980, DunBaR \& DunBar 1988). (Note that, although we use the term grooming here, in fact we could refer more generically to social time.) The generic equation used in our model (see Table 2) is a simplified version of one based on a cross-species comparison using Old World primates (LEHMANN et al. 2007b) and defines, in effect, the amount of time that is needed to maintain the social coherence of a group of a particular size through time. The original equation also incorporates effects of female dispersal and of sex ratio (species in which only males disperse show higher levels of grooming, while a strongly female-biased sex ratio decreases the amount of grooming needed). In our case, both species of ape show female dispersal to some degree (in which case the factor dispersal returns 0). Furthermore, our model does not differentiate between males and females; we therefore cannot calculate a fluctuating sex ratio, so we assumed the sex ratio in our model populations to be 1 . 
Table 2.

Statistical values for equations used in the model.

\begin{tabular}{|c|c|c|c|c|c|}
\hline Variable & Equation & $\mathrm{N}$ & $\mathrm{R}_{\text {adj }}$ & $\mathrm{F}$ & $P$ \\
\hline$\%$ fruit in diet (\%fruit) & $\begin{array}{l}169.43-50.65 * \log (\mathrm{bm})-0.02 * \text { altitude- } \\
62.02 * \mathrm{moi}_{\mathrm{momx}}+0.39 * \text { forest }_{\text {cover }}\end{array}$ & 14 & 0.83 & 16.9 & $* * *$ \\
\hline$\%$ leaves in diet (\%leaf) & 100-\%fruit & & & & \\
\hline Group biomass (grpbm) & $4.24 * \mathrm{bm}+29.83 *$ group size & 22 & 0.95 & 200 & $* * *$ \\
\hline Party size (chimps) $)^{1}$ & $21.49+0.07 *$ forest $_{\text {cover }}-0.33 * \mathrm{P}_{\mathrm{mo}}+0.0012 *\left(\mathrm{P}_{\mathrm{mo}}{ }^{2}\right)$ & 12 & 0.52 & 4.87 & $*$ \\
\hline Party size (gorilla) ${ }^{2}$ & Group size & & & & \\
\hline$\%$ feeding & $\begin{array}{c}33.09+0.005 * \operatorname{grpbm}+0.14 * \mathrm{bm}+0.16 * \% \text { fruit }- \\
0.006 * \mathrm{P}_{\mathrm{ann}}\end{array}$ & 12 & 0.84 & 15.3 & $* * *$ \\
\hline$\%$ moving & $\begin{array}{c}18.74+13.92 * \mathrm{~T}_{\mathrm{mo}} \mathrm{SD}+0.35 * \text { prtysz }-4.94 * \\
\left(\mathrm{P}_{2} \mathrm{~T}\right)+0.32 *\left(\mathrm{P}_{2} \mathrm{~T}\right)^{2}\end{array}$ & 13 & 0.76 & 7.7 & $* *$ \\
\hline$\%$ resting ${ }^{3}$ & $-29.47+1.28 * \mathrm{~T}_{\mathrm{ann}}+0.34 * \%$ leaf $+5.95 * \mathrm{~T}_{\mathrm{mo}} \mathrm{SD}$ & \multicolumn{4}{|c|}{ Generic equation } \\
\hline$\%$ grooming 4 & $1.01+0.23 *$ group size & \multicolumn{4}{|c|}{ Generic equation } \\
\hline
\end{tabular}

${ }^{1}$ Equation from LeHMANN et al. (2007a); ${ }^{2}$ because most gorillas travel as one group rather than splitting up into smaller parties, party and group size are considered to be the same; ${ }^{3}$ generic equation from KorstJENS et al. (submitted) (see text for details); ${ }^{4}$ generic equation from LEHMANN et al. (2007b); bm = body mass, moi $_{\text {momx }}=$ maximum monthly moisture index, prtysz $=$ average party size, forest cover $=$ percentage forest cover $($ derived from DE FRIES et al. 2000); $\mathrm{P}_{\mathrm{mo}}=$ average monthly rainfall $(\mathrm{mm}) ; \mathrm{P}_{\mathrm{ann}}=$ mean annual rainfall $(\mathrm{mm}) ; \mathrm{T}_{\mathrm{mo}} \mathrm{SD}=$ monthly variation in temperature; $\mathrm{P}_{2} \mathrm{~T}=$ plant productivity index (the number of months in the year in which rainfall [in $\mathrm{mm}$ ] was more than twice the average monthly temperature (LE Houérou 1984)) ; $\mathrm{T}_{\mathrm{ann}}=$ mean annual temperature. ${ }^{*} P<0.05$, $* * P<0.01$, *** $P<0.001$.

Resting time. Resting time is assumed to consist of two independent components: enforced resting time (which is driven by climate and physiology) and uncommitted resting time that is not otherwise required for feeding, moving or social activities. In order to know how much uncommitted resting time animals have available to convert into the other core activities, we need to know the minimum value of enforced resting time. Enforced resting time is most likely to be a consequence of the fact that animals need time to digest food and are unable to engage in energetically costly activities when ambient temperatures rise above a critical threshold (and are thus forced to rest). Unfortunately, values for resting time given in the literature do not usually allow us to distinguish between the two components of resting time. We therefore use a generic equation derived from a comparative study using 78 species of primates (KoRsTJENS et al. submitted). This study found that enforced resting time was determined by the percentage of leaves in the diet (i.e. digestion time), ambient temperature and temperature variation (see Table 2).

\section{Model procedure}

The model uses the equations for the above variables to calculate for each of the sites in our database the maximum ecologically tolerable group size, following the procedure described in DunBar (1992b). The model starts with a group size of one individual and calculates that individual's time budget. If the sum of the time budget variables does not exceed $100 \%$, group size is then increased algorithmically by one individual 
at a time until the sum of all time budget variables exceeds $100 \%$; the maximum ecologically tolerable group size is then defined as the group size of the previous cycle. In order to avoid anomalous outcomes, all time budget equations were constrained to have minimum values of $5 \%$ and maximum values of $99 \%$. In addition, party size was not allowed to exceed group size and was constrained to a minimum of one individual. Because the model is based on body mass, we consider two distinct weight categories to represent Pan $(40 \mathrm{~kg})$ and gorillas $(120 \mathrm{~kg})$, respectively. These body masses correspond roughly to the mean weight of a male and female Pan and Gorilla. Differences in social system (fission-fusion in Pan versus cohesive groups in gorillas) were modelled by using party size and group size respectively to determine moving time for Pan and gorillas.

Because we do not have a method to predict what the minimum viable group size is for apes (i.e. the cut-off value in the model that defines whether or not apes can survive in a given habitat), we ran a sensitivity analysis using a range of different cut-off values to determine how sensitive the model was to this variable.

\section{Model validation and test}

The model was validated in two ways. First, we tested how accurately the model predicts the presence and absence of apes in forested National Parks across subSaharan Africa for which we know whether or not apes are present. Data on presence and absence of apes across Africa were obtained by screening the primate literature and the Internet, especially the UNEP and WMCM World database on protected areas (UNEP-WCPA) and from GRASP (BUtYNSKi 2001, Kormos et al. 2003, CaldecotT \& MILEs 2005). To preserve statistical independence, only sites separated from each other by at least $0.5^{\circ}$ longitude and latitude were included. This dataset consists of 639 independent sites across Africa, 380 of which reported the presence of Pan, while gorillas were present at 110 sites (including the sites from Table 1). Second, we test how accurately the model predicts group size at those sites where group size is known.

\section{Statistics}

Data on Pan behaviour were tested for normality using the Kolmogorov-Smirnov test. For screening the data and the relations between ecological and time budget variables, we used scatter plots (to find possible curvilinear relations) as well as bivariate Pearson correlation analyses. Linear regression and curvilinear estimation procedures (such as quadratic or logarithmic functions) were then used to obtain multivariate equations for each dependent variable of interest. Finally, we used a linear program in Dbase to calculate maximum ecologically tolerable group size for each location in the dataset. Because predicted values were not normally distributed, we used one-sided Wilcoxon Signed Ranks tests (WSR) to compare predicted and observed values, and MannWhitney-U tests (MWU) to compare predicted group sizes and time budget components between correctly and falsely classified sites.

\section{RESULTS}

\section{Equations}

The equations used by the model are given in Table 2 while Fig. 1 presents a flowchart of the ecological relationships and the competitive regimes as 


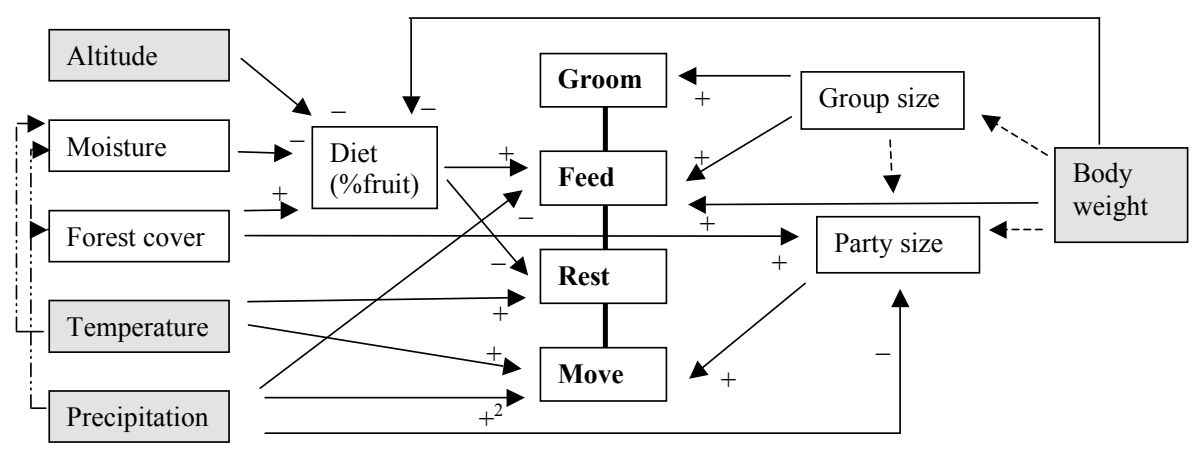

Fig. 1. - Flow chart of the relationships between climate, ape diet, body weight, group size and time budget variables as used in the model. Solid arrows indicate relationships used in the model, dashed arrows indicate relationships that are 'optional', depending on the strategy used by a species and dashed-dotted arrows indicate interdependency in climate variables which, however, were not used in this model. True independent variables are those in grey boxes.

obtained from the observational data in Table 1 and subsequently used by the model. All equations used in the model were significant and had an adjusted $r$ between 0.5 and 0.95 (see Table 2). The fact that body mass was found to be an important independent predictor for diet and time budget variables justifies our use of two distinct weight categories for Pan and gorillas respectively. In addition, party biomass was found to be an important predictor for feeding time. Because we originally based feeding group biomass on exact calculations derived from group composition and because the model does not distinguish between groups of different compositions, we aimed at finding an equation that would enable us to predict party biomasses reliably. The resulting equation derived from linear regression (by excluding the intercept) is based on species body mass and group size (Table 2). This equation is a conservative measure of sub-group biomass as it is likely to underestimate biomasses for large groups. However, we also ran the model using the more traditional method of calculating group biomass based on average body weight multiplied by number of individuals and found that both equations provided identical results in terms of distribution patterns but differed slightly in group size estimations (with our equations providing larger estimates). Because our equation models the observed values which were used in the equation finding processes more closely, we used this one in the final model. Total group size and party size, on the other hand, were found to be important for moving time and grooming time calculations. The percentage of fruits in the diet could be predicted from ape body mass, altitude, moisture and forest cover, and \% leaves in diet was assumed to account for the remainder. Moving time was determined by temperature seasonality, rainfall seasonality and feeding group size ( i.e. party size in Pan and group size in gorillas).

\section{Validation}

Minimum viable group size. We first need to establish an appropriate minimum viable group size for each taxon since there must always be a group 
size below which any species cannot survive (DUNBAR 1996). Since the minimum viable group size is not really known for either taxon (it is not necessarily the same as the smallest group size ever observed), we ran a sensitivity analysis in which minimum viable group size varied systematically between 5-50 individuals. We ran the model using the climatic data for the sites in our African database. Because, for these sites, we know whether or not apes are present, we can compare the model output with real observations. Table 3 indicates the model's performance as a function of these minimum viable group sizes. The important metric here is how well the model predicts actual presence for each taxon.

Biogeography. Table 4 shows the distribution of correct and false predictions against ape presence/absence at all the sites in our database. For Pan, the model correctly predicts presence/absence in $74 \%$ of all cases, while presence and absence for gorillas is correctly predicted in $62 \%$ of cases. While by no means perfect, both sets of predictions are significantly better than chance $\left(\mathrm{G}_{\text {chimp }}=349.3, \mathrm{n}_{\text {chimp }}=639, \mathrm{df}_{\text {chimp }}=1, P_{\text {chimp }}<0.0001 ; \mathrm{G}_{\text {gor }}=109.2, \mathrm{n}_{\text {gor }}=639\right.$, $\left.\mathrm{df}_{\text {gor }}=1, P_{\text {gor }}<0.0001\right)$. When combining both apes (Table $4 \mathrm{c}$ ), it becomes evident that according to the model there are no sites at which only gorillas can survive; instead, the majority of sites are classified as suitable for both Pan and Gorilla.

The model provides a good fit to known Pan and Gorilla distributions (Fig. 2), but generally appears to overestimate the extent of their distribution into East Africa and towards the south (e.g. into Angola). Although our model identifies these habitats as being more suitable for Pan than for gorillas, Pan are not known ever to have existed in these regions. Similarly, the heavier gorillas are predicted to be present not only within their present distribution but also in the more central areas linking the separate parts of the gorilla's currently disjunctive distribution. In addition, the model also indicates that some areas of West Africa as well as the forests south of the Congo River provide

Table 3.

The accuracy (correct predictions, $\%$ ) of the model in predicting presence and absence of apes at independent sites as a function of the minimum viable group size we use as a cut-off value.

\begin{tabular}{lcccccc}
\hline \multirow{2}{*}{$\begin{array}{l}\text { Minimum group } \\
\text { size cut-off }\end{array}$} & \begin{tabular}{c} 
Pan \\
\% present \\
\cline { 2 - 7 }
\end{tabular} & $\begin{array}{c}\text { \% absent } \\
(\mathrm{n}=259)\end{array}$ & $\begin{array}{c}\text { \% overall } \\
\text { correct }\end{array}$ & $\begin{array}{c}\text { \% present } \\
(\mathrm{n}=110)\end{array}$ & $\begin{array}{c}\% \text { absent } \\
(\mathrm{n}=529)\end{array}$ & $\begin{array}{c}\% \text { overall } \\
\text { correct }\end{array}$ \\
\hline 5 & 93.4 & 42.9 & 72.9 & 86.4 & 57.3 & 62.3 \\
10 & 93.2 & 45.6 & 73.9 & 82.7 & 65.0 & 68.1 \\
15 & 92.1 & 50.6 & 75.3 & 55.5 & 71.8 & 69.0 \\
20 & 90.5 & 55.2 & 76.2 & 22.7 & 82.6 & 72.3 \\
30 & 86.6 & 64.9 & 77.8 & 0.9 & 98.7 & 81.8 \\
40 & 80.3 & 72.2 & 77.0 & 0.0 & 100.0 & 82.8 \\
50 & 72.1 & 79.5 & 75.1 & 0.0 & 100.0 & 82.8 \\
\hline
\end{tabular}


Table 4.

Observed and predicted occurrences of (a) Pan $40 \mathrm{~kg}$ and (b) gorillas $120 \mathrm{~kg}$ and (c) both apes together across Africa (values represent number of sites).

(a)

\begin{tabular}{|c|c|c|c|c|}
\hline & \multicolumn{4}{|c|}{ Observed } \\
\hline & $40 \mathrm{~kg}$ & Present & Absent & Total \\
\hline \multirow{3}{*}{ 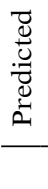 } & Present & 354 & 141 & 495 \\
\hline & Absent & 26 & 118 & 144 \\
\hline & Total & 380 & 259 & 639 \\
\hline
\end{tabular}

(b)

\begin{tabular}{|c|c|c|c|c|}
\hline & \multicolumn{4}{|c|}{ Observed } \\
\hline & $120 \mathrm{~kg}$ & Present & Absent & Total \\
\hline \multirow{3}{*}{ 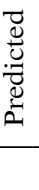 } & Present & 94 & 217 & 311 \\
\hline & Absent & 16 & 312 & 328 \\
\hline & Total & 110 & 529 & 639 \\
\hline
\end{tabular}

(c)

\begin{tabular}{|c|c|c|c|c|c|c|}
\hline & \multicolumn{5}{|c|}{ Observed } \\
\hline & & Absence & Pan only & Gorilla only & Both apes & Total \\
\hline \multirow{5}{*}{ 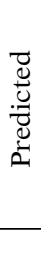 } & Absence & 118 & 26 & 0 & 0 & 144 \\
\hline & Pan only & 91 & 77 & 2 & 14 & 184 \\
\hline & Gorilla only & 0 & 0 & 0 & 0 & 0 \\
\hline & Both apes & 42 & 175 & 6 & 88 & 311 \\
\hline & Total & 251 & 278 & 8 & 102 & 639 \\
\hline
\end{tabular}

suitable habitats for gorillas. While these locations may indeed provide suitable habitat for gorillas, it is clear in this case that geographical barriers (such as the Congo River, the Dahomey Gap and the presence of intervening savannah belts south of the Congo and in the east on the Rift valley floor) have prevented gorillas from inhabiting these locations. It is less clear, however, why gorillas do not now occur to the north of the Congo River (in DRC). Our model indicates that this relatively small stretch of forest (limited in the north by the Ubangi River) would provide suitable habitat for gorillas and, given their current distribution, gorillas clearly must have once lived in these regions.

Predicted group sizes. Overall, predicted ape group sizes are strongly dependent on body weight. Under present climate conditions, predicted Pan group sizes averaged $65 \pm 21$ (mean $\pm \mathrm{SD}, \mathrm{n}=354$ ) at sites where Pan were correctly predicted to be present, while predicted Gorilla group size averaged $17 \pm 6$ (mean \pm SD, $\mathrm{n}=94)$. These values are well within the observed range for Pan and Gorilla groups (means of $54 \pm 28$ and $11 \pm 8$ individuals, respectively; $\mathrm{n}=13$ for Pan and $\mathrm{n}=19$ for Gorilla). Fig. 3 compares the predicted values for group size at sites where apes were correctly predicted to be present with those actually observed at specific sites. Recall that the model 


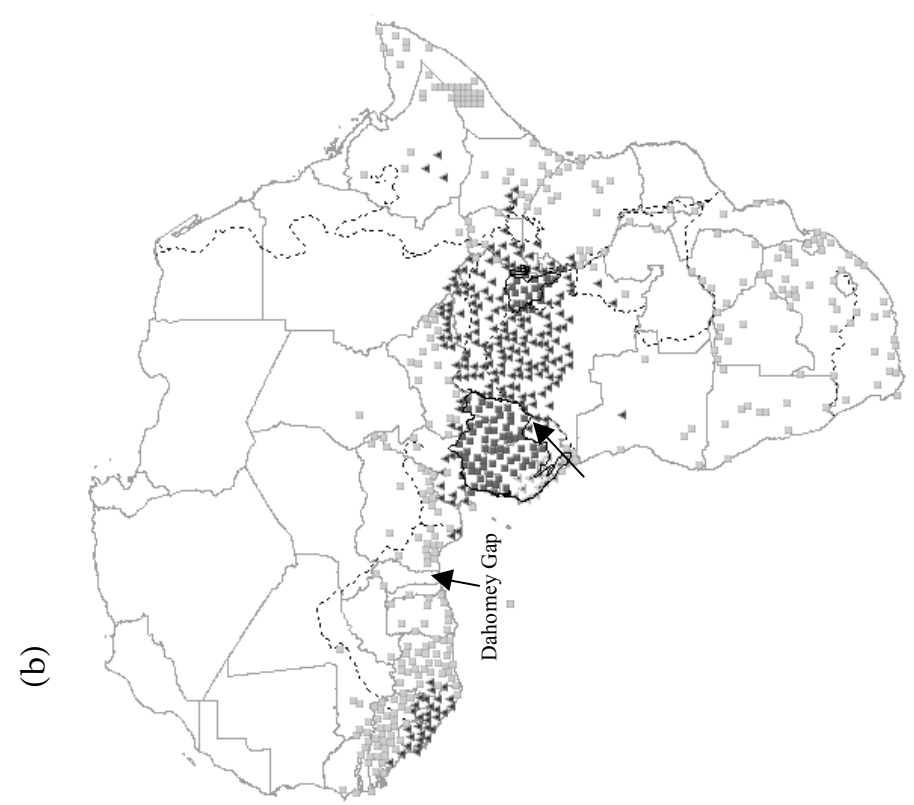

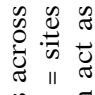

幽

के

离: $\frac{0}{3} \cdot \frac{3}{3}$

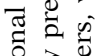

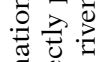

ठृ

के

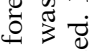

¿

过

要远

훙 둥

쿠

ن

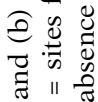

ह

สิ

t)

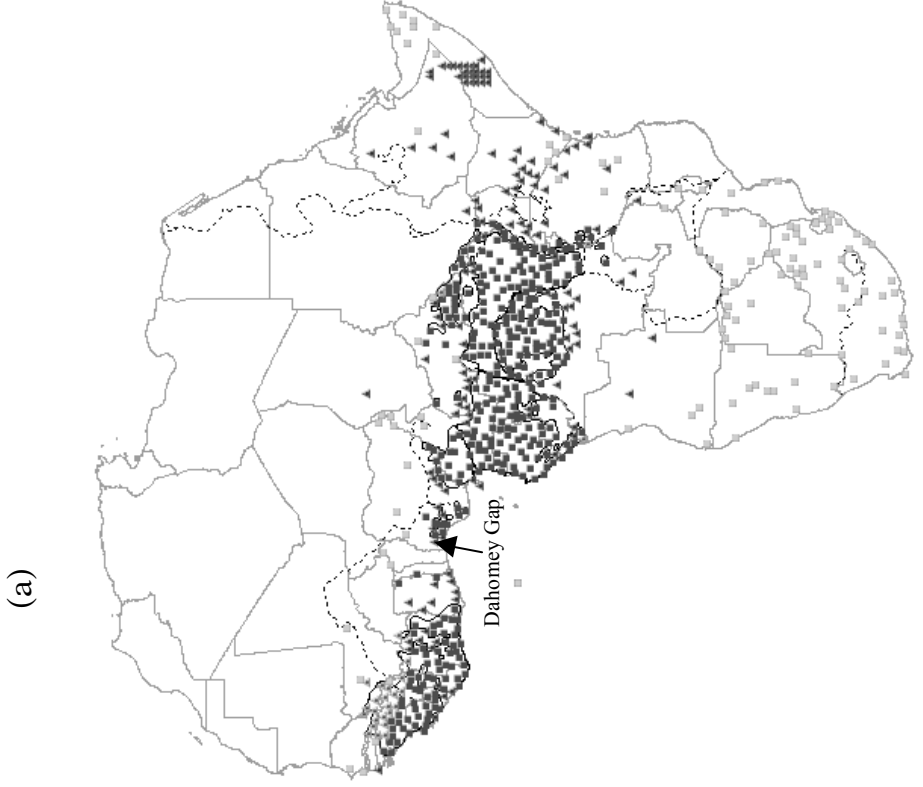

\&

政

क्ष

둥

ช

菏

过気

पु

원

च

묵

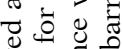

\&

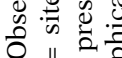

| - 도ำ

ㄱ

樆运它。 


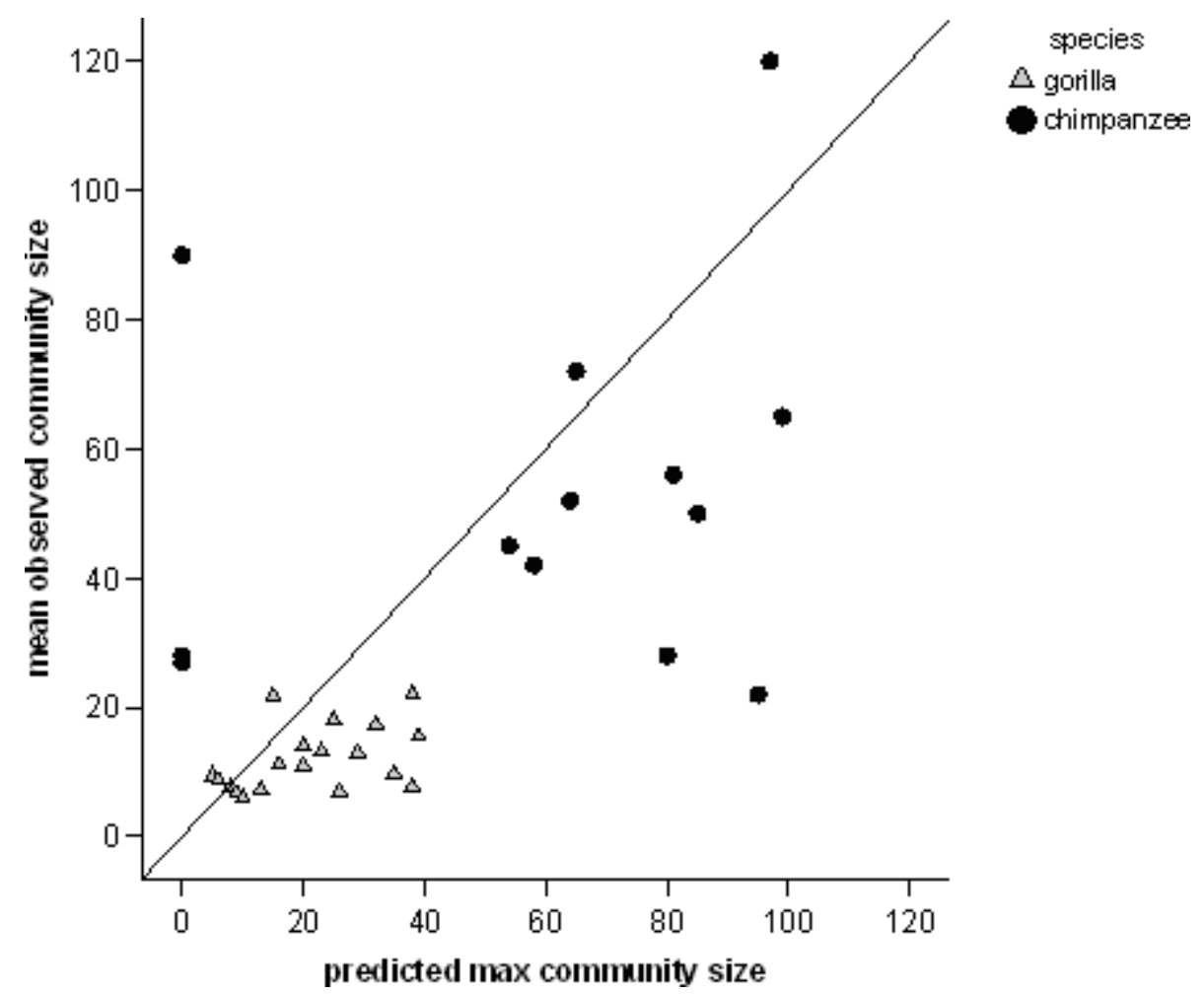

Fig. 3. - Comparison of predicted (by the model) with actually observed group sizes for Pan (black circles) and gorillas (grey triangles). Note that values should fall on or below the diagonal (which indicates equal values), because the model will predict maximum ecologically tolerable group sizes, which should be higher or equal to those observed in the field.

is designed to predict the maximum ecologically tolerable group size: predicted group sizes should thus lie below the main diagonal of the graph (the line that demarcates points where observed and predicted values are the same). Predicted maximum group sizes are significantly larger than mean observed group sizes for both Pan (WSR: $\mathrm{n}=10, \mathrm{z}=2.2, P=0.027$ ) and for Gorilla (WSR: $\mathrm{n}=17, \mathrm{z}=3.1, P=0.002$ ), but do not differ significantly from maximum observed values (WSR: Pan: $\mathrm{n}=10, \mathrm{z}=1.2, P=0.2 ;$ Gorilla: $\mathrm{n}=17, \mathrm{z}=$ $0.5, P=0.62$ ), indicating that these apes only occasionally live in groups that are close to their ecological maximum.

In order to evaluate whether group sizes are consistently smaller at sites for which the model falsely predicted apes to be present (false positives), we compared predicted group sizes for sites at which apes were correctly predicted to be present with those where they were falsely predicted to be present (Fig. 4). This comparison shows that, for Pan, predicted group sizes at false positive sites are significantly smaller than those at correctly predicted sites (median of 41 individuals for false positives, versus 70 individuals at correct 


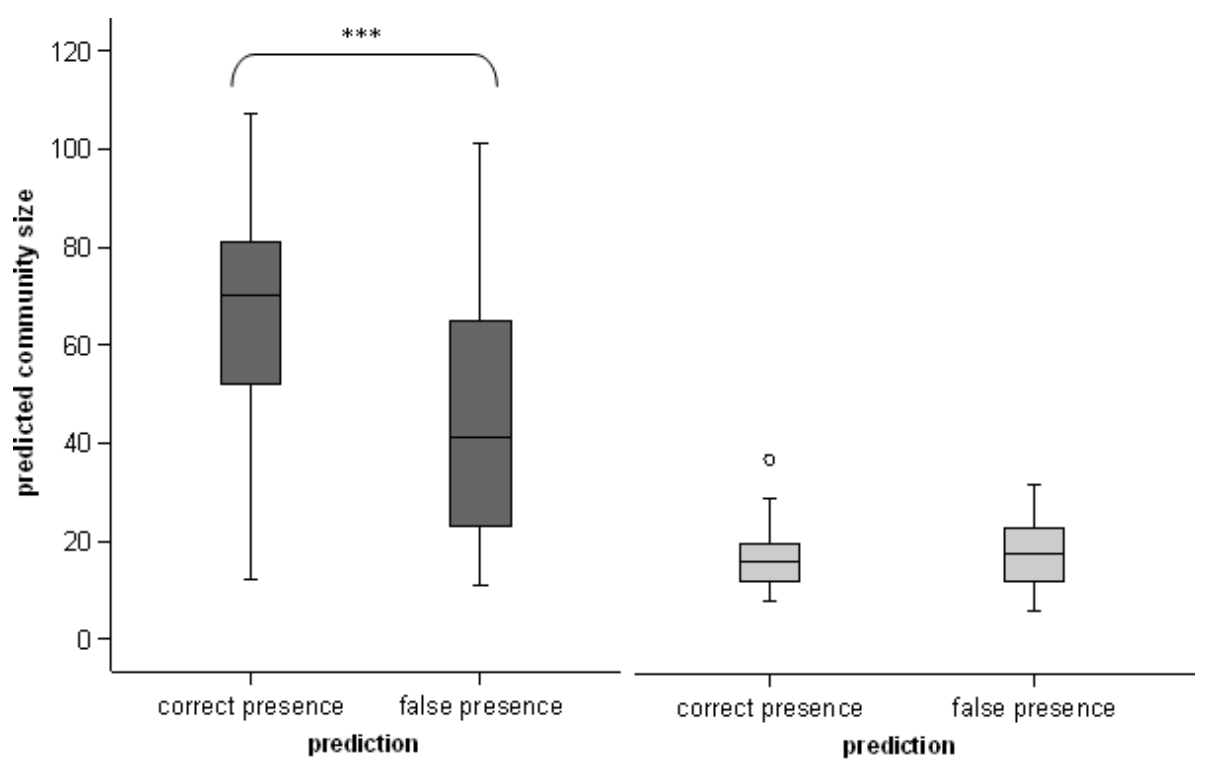

Fig. 4. - Boxplots of predicted group sizes for Pan (dark grey) and Gorilla (light grey) at sites where they were correctly and falsely predicted to be present. These graphs suggest that Pan may need a minimum group size that is closer to 40 than to the conservative value of 10 used in this model, while this is not the case for Gorilla. ${ }^{* * *} P<0.001$.

sites; MWU: $\mathrm{z}=7.9, \mathrm{n}=495, P<0.0001$; Fig. 4). This suggests that were chimpanzees to try living in these habitats, they would be forced to live in very small communities, many of which would be well below the smallest community sizes actually observed (see also LEHMANN et al. 2007a). [Note that using a minimum viable group size of 20 individuals instead of 10 individuals for Pan in the model would not change these results, as predicted group sizes are considerably larger than both these values (see Fig. 4)]. For gorillas, on the other hand, the difference in predicted group sizes for correctly predicted presence sites as compared to those where they are falsely predicted to be present is not significant (18 individuals for false positives, versus 17 individuals at correctly predicted sites; MWU: $\mathrm{z}=-1.3, \mathrm{n}=311, P>0.1$; Fig. 4$)$. This suggests that the cut-off value of 5 individuals as used in the model for larger bodied apes is realistic.

\section{Time budgets and biogeography}

In order to evaluate which time budget components drive the distribution patterns of apes across Africa, we compared moving, resting and feeding times at sites where apes were correctly predicted to be present with those where they were correctly predicted to be absent (Fig. 5). Note, that moving and feeding time are influenced by group size (which, by definition, is higher 
(a)

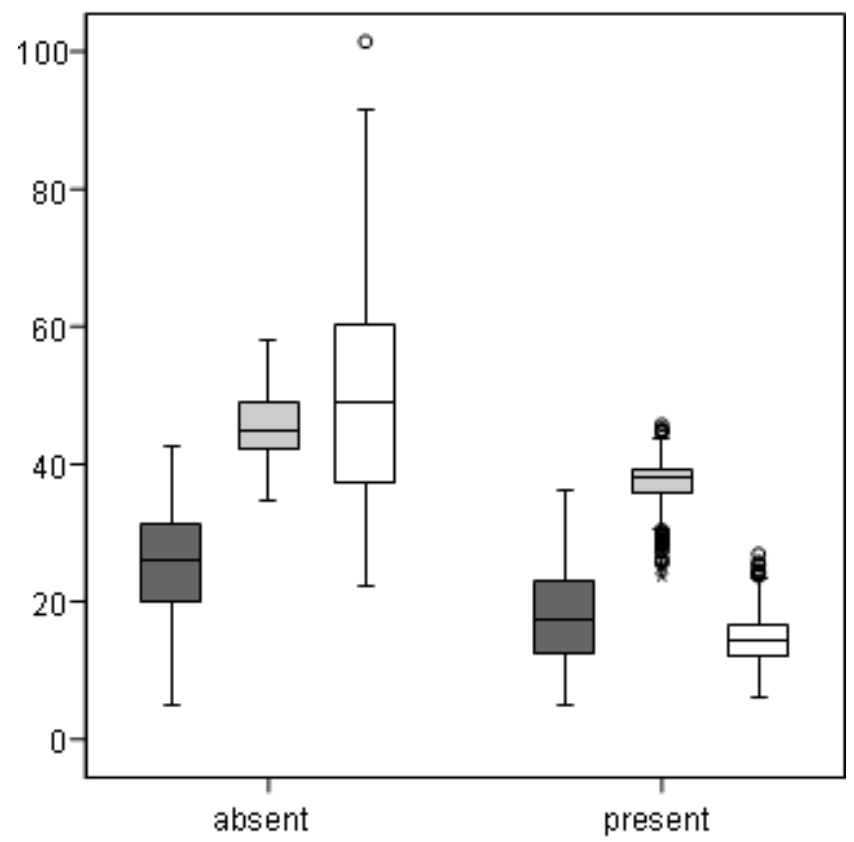

(b)

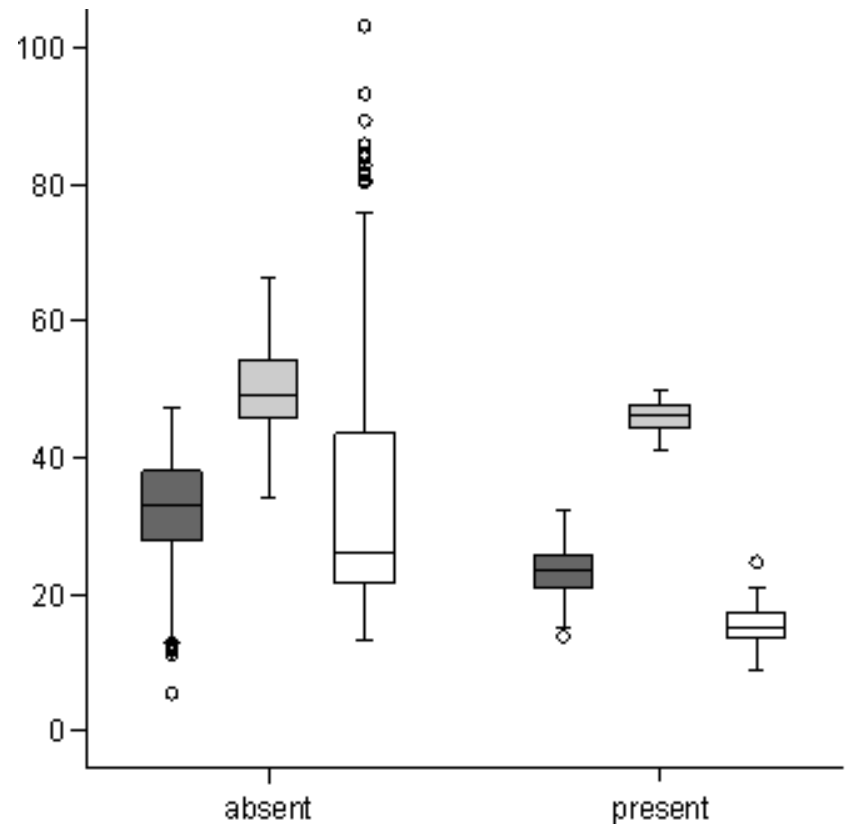

Fig. 5. - Box plot of time budget variables of Pan (a) and Gorilla (b) at sites where they are correctly predicted to be absent and sites where they are correctly predicted to be present. Dark grey $=$ resting, light grey $=$ feeding and white $=$ moving. Feeding and moving time are calculated based on party and group size of 5 and 10 individuals, respectively. 
at sites where apes are present as compared to those where they are absent). To be able to compare time budget components across sites and body weights, we calculated mean feeding, moving and resting time for a constant group size (an arbitrarily chosen 10 individuals, splitting into two parties in case of Pan). For both Pan and Gorilla, feeding, moving and resting times were significantly higher at sites, where they are absent as compared to sites where

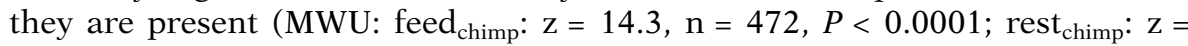
8.6, $\mathrm{n}=472, P<0.0001$; move $_{\text {chimp }}: \mathrm{z}=16.2, \mathrm{n}=472, P<0.0001$; feed gor $_{0}: \mathrm{z}=$ 6.9, $\mathrm{n}=406, P<0.0001$; rest gor $_{1}: \mathrm{z}=9.5, \mathrm{n}=406, P<0.0001 ;$ move $_{\text {gor }}: \mathrm{z}=13.9$, $\mathrm{n}=406, P<0.0001)$. However, absolute differences in the time budget components were, for both species, largest for moving time and smallest for feeding time (see Fig. 5), indicating that it is primarily moving time that prevents apes from occurring outside their current biogeographical distribution.

A comparison of time budget variables at sites for which the model incorrectly predicted Pan to be present (false positives) with those where they were correctly predicted to occur may indicate why apes do not live there, even though they could according to the model. Such a comparison suggests that Pan have significantly higher feeding (MWU: $\mathrm{z}=-6.5, \mathrm{n}=495, P<0.0001$ ) and moving times (MWU: $\mathrm{z}=-6.3, \mathrm{n}=495, P<0.0001$ ) at false positive sites as compared to those were they are correctly predicted to be present. Pan would thus have to spend more time feeding and travelling at those sites where they do not occur and would therefore have to live in smaller groups, which may force them to compromise on the demands that seem to oblige them to live in fairly large communities (typically > 45 individuals: see above, and LEHMANN et al. 2007a). For gorillas, on the other hand, only moving time was found to be significantly higher at false positive sites (MWU: $\mathrm{z}=-2.5, \mathrm{n}=311, P<$ $0.02)$, although the absolute difference in moving time was very small $(\sim 1 \%)$. This suggests that there are fundamental differences between the two species in terms of the limits on their biogeographical distribution: Pan appears to be restricted by the minimum group size they can sustain within a given habitat, while the gorilla's biogeographical range appears to be more strongly limited by the existence of geographical barriers that they cannot cross.

\section{DISCUSSION}

Considering the simplicity of the model's premises, it produces a remarkably good fit to present day Pan and Gorilla distributions. Of course, given the way human influences and the dramatic level of deforestation across many African regions restrict present day ape distribution patterns, some deviations from observed patterns are to be expected. Such anthropogenic effects were not included in our model, mainly because our focus has been on evaluating the effect of climate conditions.

Compared to previous time budget models (DUNBAR 1992a, 1992b; WILLiamson \& Dunbar 1999; KorstJens et al. 2006; KorstJens \& Dunbar 2007), this model adds new layers of complexity by stressing the role of variables such as body mass, and diet in the evolution of ape social systems and bio- 
geography. The results also demonstrate, that both the African great apes share a similar underlying ecological bauplan, with the principal differences between them being largely a reflection of contrasts in body weight. For both species, it is the demands of travel time that ultimately seem to impose the greatest constraints on their ability to colonise a wider range of habitats in sub-Saharan Africa. In terms of diet, both Pan and Gorilla appear to prefer fruit when available. (Note that, even though gorillas are often characterized as being predominantly folivorous, their molar teeth are more similar to those of other frugivorous apes than to those of folivores: MARTIN 1990). However, during low food availability gorillas, unlike Pan, fall back on a diet consisting predominantly of leaves (UNGAR 2004), in part at least because their large body size prevents them from reaching fruit while at the same time allowing them to digest large quantities of leaves (MARSHALL \& WRANGHAM 2007). However, in doing so, gorillas pay an additional time budget cost: the higher percentage of non-fruit (i.e. leafage) in their diet imposes an additional demand for resting time (mainly to allow digestion). Since their smaller body size allows Pan to avoid this problem, Pan is able to survive in a wider range of habitats than Gorilla.

It has been known for a long time that bioegeographical barriers have prevented apes from colonizing certain otherwise suitable areas: the Dahomey Gap and the size of the Niger and Congo rivers are most likely the reasons why gorillas do not occur in West Africa and in the forests within the Congo River loop (KoRTLANDT 1995). Our model confirms that areas like the Dahomey Gap are difficult for (large-bodied) apes to colonise, and thus cross. Although the model suggests that Pan could live further south than their current distribution, it may be that high predation risk in the belt of open savannah that fringes the southern boundary of the Congo forest block prevents them from doing so. While the Congo River is probably too wide for either Pan or Gorilla to cross throughout most of its range, Fig. 3 suggests that Pan can extend its range just far enough southwards down the eastern bank to get around into the Congo basin - especially in the past when cooler, wetter climates might have meant that the forest belt extended just a little further southwards along the Rift Valley edge. In contrast, the stronger constraints on the gorillas' ecological flexibility leave them stranded just a little too far to the north. Presumably, the Dahomey Gap provides an analogous problem for the gorillas. Fig. 3 suggests that Pan are able to bridge the Gap because their natural range extends over a much wider area here. Gorillas could live in the vicinity of Sierra Leone and Liberia, but the gap they would have to cross to get there is 10 times larger than that for Pan. The fact that there are no gorillas in West Africa suggests that the gap has always been too wide for gorillas to spread that far west, even under past climatic conditions when the climate may have been cooler and wetter and the west African forest block more extensive.

The only region where the model really fails to predict the known presence of Pan is in the northern parts of West Africa. These parts of Africa constitute marginal habitat for Pan and little is known about the behaviour of chimpanzees in this area. It may be significant that West African Pan are less heavy than the central and eastern subspecies (CALDECOTT \& Miles 2005), so that using a body mass value of $40 \mathrm{~kg}$ as we did in the model may be imposing an artifi- 
cial restriction on the West African subspecies. A lower body mass may enable Pan to live in otherwise marginal areas by reducing some of their feeding costs.

Taken together, time budget models enable us to understand the mechanisms behind individual behaviour and species distributions better. In addition, they provide insight into what it is that prevents a particular species from living in some habitats, and this potentially has great relevance to conservation biology. Furthermore, these models are based on relatively simple climate parameters and can thus provide a window by which we may glimpse into the future (e.g. to investigate the effects of climate change on species distribution) and the past (e.g. by investigating distribution patterns in prehistoric times).

\section{ACKNOWLEDGMENTS}

Julia Lehmann was funded by the British Academy Centenary Research Project, and Amanda H. Korstjens by a grant from the Leverhulme Trust. Robin I.M. Dunbar was supported by a British Academy Research Professorship.

\section{REFERENCES}

Altmann J. 1980. Baboon mothers and infants. Princeton: Harvard University Press.

BEAN A.E. 1998. The ecology of sex differences in great ape foraging behaviour \& huntergatherer subsistence behaviour. PhD Thesis, Department of Biological Anthropology, University of Cambridge.

Blake S., Rogers E., Fay J.M., Ngangoue M. \& Ebeke G. 1985. Swamp gorillas in northern Congo. African Journal of Ecology 33: 285-290.

Boesch C. 1996. Social grouping in Tai chimpanzees, pp. 101-113. In: Mcgrew W.C. et al., Edits. Great ape societies. Cambridge: Cambridge University Press.

Boesch C. \& Boesch-Achermann H. 2000. The chimpanzees of the Taï Forest: Behavioural Ecology and Evolution. Oxford: Oxford University Press.

ButYNSKI T.M. 2001. Africas Great apes, pp. 3-56. In: Beck B. et al., Edits. Great apes and humans; ethics of coexistence. Washington DC, USA: Smithsonian Institution Press.

Caldecott J. \& Miles L. 2005. World Atlas of Great Apes and their Conservation. Prepared at the UNEP World Conservation Monitoring Centre. Berkeley, USA: University of California Press.

CASIMIR M.J. 1975. Feeding ecology and nutrition of an eastern gorilla group in Mt Kahuzi Region (Republique-du-Zaire). Folia Primatologica 24: 81-136.

Chapman C.A., Wrangham R.W. \& Chapman L.J. 1995. Ecological constraints on groupsize - an analysis of spider monkey and chimpanzee subgroups. Behavioral Ecology and Sociobiology 36: 59-70.

Cipolletta C. 2003. Ranging patterns of a western gorilla group during habituation to humans in the Dzanga-Ndoki National Park, Central African Republic. International Journal of Primatology 24: 1207-1226.

Clutton-Brock T.H. 1977. Primate ecology: Studies of feeding and ranging behaviour in lemurs, monkeys and apes. London: Academic Press.

De Fries R., Hansen M., Townshend J.R.G., Janetos A.C. \& Loveland T.R. 2000. Continuous fields $1 \mathrm{~km}$ tree cover. College Park, Maryland: The Global Land Cover Facility. 
DORAN D. 1997. Influence of seasonality on activity patterns, feeding behavior, ranging, and grouping patterns in Tai chimpanzees. International Journal of Primatology 18: 183-206.

Doran D.M. 1996. Comparative positional behavior in great apes, pp. 213-224. In: Mcgrew W.C. et al., Edits. Great ape societies. Cambridge: Cambridge University Press.

Doran D.M. \& McNeILage A. 1998. Gorilla ecology and behavior. Evolutionary Anthropology 6: 120-131.

Doran D.M. \& McNeIlage A. 2001. Subspecific variation in gorilla behavior: the influence of ecological and social factors, pp. 123-149. In: Robbins M. et al., Edits. Mountain Gorillas: Three decades of research at Karisoke. New York: Cambridge University Press.

Doran D.M., McNeilage A., Greer D., Bocian C., Mehlman P. \& Shah N. 2002. Western lowland gorilla diet and resource availability: New evidence, cross-site comparisons, and reflections on indirect sampling methods. American Journal of Primatology 58: 91-116.

Doran-Sheehy D.M., Greer D., Mongo P. \& Schwindt D. 2004. Impact of ecological and social factors on ranging in western gorillas. American Journal of Primatology 64: 207-222.

DunBar R.I.M. 1992a. A model of the gelada socioecological system. Primates 33: 69-83.

DunBAR R.I.M. 1992b. Time: A hidden constraint on the behavioural ecology of baboons. Behavioral Ecology and Sociobiology 31: 35-49.

DunBaR R.I.M. 1996. Determinants of group size in primates: a general model. Proceedings British Academy 88: 33-57.

Dunbar R.I.M. \& Dunbar P. 1988. Maternal time budgets of Gelada Baboons. Animal Behaviour 36: 970-980.

FAWCETT K.A. 2000. Female relationships and food availability in a forest community of chimpanzees. PhD Thesis: University of Edinburgh.

Fossey D. 1974. Observations on Home Range of One Group of Mountain Gorillas (Gorilla gorilla beringei). Animal Behaviour 22: 568-581.

Ganas J., Robbins M.M., NkuRunungi J.B., Kaplin B.A. \& McNeilage A. 2004. Dietary variability of mountain gorillas in Bwindi Impenetrable National Park, Uganda. International Journal of Primatology 25: 1043-1072.

GHIGLIERI M.P. 1984. Feeding ecology and sociality of chimpanzees in Kibale Forest, Uganda, pp. 161-194. In: Rodman P.S. \& Cant J.G.H., Edits. Adaptations for foraging in nonhuman primates. New York: Columbia University Press.

GoldSMITH M.L. 1999. Ecological constraints on the foraging effort of western gorillas (Gorilla gorilla gorilla) at Bai Hokou, Central African Republic. International Journal of Primatology 20: 1-23.

GoodALl A.G. 1977. Feeding and ranging behavior of a mountain gorilla group (Gorilla gorilla beringei) in the Thibinda-Kahuzi region (Zaire), pp. 450-479. In: CluttonBrock T.H., Edit. Primate ecology. New York: Academic Press.

Goodall J. 1968. The behaviour of free-living chimpanzees in the Gombe Stream area. Animal Behaviour Monographs 1: 161-311.

Goodall J. 1983. Population-dynamics during a 15 year period in one community of free-living chimpanzees in the Gombe National Park, Tanzania. Zeitschrift für Tierpsychologie (Journal of Comparative Ethology) 61: 1-60.

Goodall J. 1986. The chimpanzees of Gombe: Patterns of behavior. Cambridge: The Belknap Press of Harvard University Press.

Hill R.A. \& DunBaR R.I.M. 2002. Climatic determinants of diet and foraging behaviour in baboons. Evolutionary Ecology 16: 579-593.

ILAMBU O. 2001. Ecology of eastern lowland gorilla: is there enough scientific knowledge to mitigate conservation threats associated with extreme disturbances in its distribution range?, pp. 307-312. In: The Apes: challenges for the 21st century. Conference Proceedings. Brookfield: Brookfield Zoo. 
Jones C. \& SABATER Pi J. 1971. Comparative ecology of Gorilla gorilla (Savage and Wyman) and Pan troglodytes (Blumenbach) in Rio Muni, West Africa. Basel: S. Karger.

Kano T. \& Mulavwa M. 1984. Feeding ecology of the pygmy chimpanzees (Pan paniscus) of Wamba, pp. 233-274. In: Susman R.L., Edit. The pygmy chimpanzee. New York: Plenum Press.

Kormos R., Boesch C., Bakarr M.I. \& Butynski T.M. (Edits) 2003. West African chimpanzees. Status survey and conservation action plan. Gland, Switzerland and Cambridge: IUCN.

Korstjens A.H. \& DunBar R.I.M. 2007. Time constraints limit group sizes and distribution in red and black-and-white colobus monkyes. International Journal of Primatology 28: 555-575.

KorstJens A.H., Lehmann J. \& Dunbar R.I.M. (submitted). Resting time as a constraint on primate biogeography.

Korstjens A.H., Verhoekx I.L. \& Dunbar R.I.M. 2006. Time as a constraint on group size in spider monkeys. Behavioral Ecology and Sociobiology 60: 683-694.

Kortlandt A. 1995. An ecosystem approach to hominid and ape evolution, pp. 87-97. In: Bower J. \& Sartono S., Edits. Human evolution in its ecological context: Paleo-anthropology, Evolution and Ecology of Homo erectus. Leiden: Pithecanthropus Centennial Fdn.

KURODA S. 1979. Grouping of the pygmy chimpanzees. Primates 20: 161-183.

LE Houérou H.N. 1984. Rain use efficiency - a unifying concept in arid-land ecology. Journal of Arid Environments 7: 213-247.

Legates D.R. \& Willmott C.J. 1990a. Mean seasonal and spatial variability in gaugecorrected, global precipitation. International Journal of Climatology 10: 111-127.

Legates D.R. \& Willmott C.J. 1990b. Mean seasonal and spatial variability in global surface air temperature. Theoretical and Applied Climatology 41: 11-21.

LehmanN J. \& Boesch C. 2003. Social influences on ranging patterns among chimpanzees (Pan troglodytes verus) in the Taï National Park, Côte d'Ivoire. Behavioral Ecology 14: 642-649.

LEHMANN J. \& BoEsch C. 2004. To fission or to fusion: effects of community size on wild chimpanzee (Pan troglodytes verus) social organisation. Behavioral Ecology and Sociobiology 56: 207-216.

Lehmann J., KorSTJEns A.H. \& Dunbar R.I.M. 2007a. Fission-Fusion social systems as a strategy for coping with ecological constraints: a primate case. Evolutionary Ecology 21: 613-634.

Lehmann J., KorstJens A.H. \& Dunbar R.I.M. 2007b. Group size, grooming and social cohesion in primates. Animal Behaviour 74: 1617-1629.

Lehmann J., KorstJens A.H. \& Dunbar R.I.M. 2008. Time Management in Great Apes: Implications for Gorilla Biogeography. Evolutionary Ecology Research 10: 517-536.

Marshall A.J. \& Wrangham R.W. 2007. Evolutionary consequences of fallback foods. International Journal of Primatology 28: 1219-1235.

MARTIN R.D. 1990. Primate origins and evolution. London: Chapman \& Hall.

Matsumoto-Oda A. 2002. Behavioral seasonality in Mahale chimpanzees. Primates 43: 103-117.

Matsumoto-Oda A., HosaKa K., Huffman M.A. \& Kawanaka K. 1998. Factors affecting party size in chimpanzees of the Mahale mountains. International Journal of Primatology 19: 999-1011.

McGRew W.C., Baldwin P.J. \& Tutin C.E.G. 1988. Diet of wild chimpanzees (Pan troglodytes verus) at Mt. Assirik, Senegal: I. Composition. American Journal of Primatology 16: 213-226.

Mitani J.C., Watts D.P. \& Lwanga J.S. 2002. Ecological and social correlates of chimpanzee party size and composition, pp. 102-111. In: Boesch C. et al., Edits. Behavioural diversity in chimpanzees and bonobos. Cambridge: Cambridge University Press. 
Newton-Fisher N.E. 1999. The diet of chimpanzees in the Budongo Forest Reserve, Uganda. African Journal of Ecology 37: 344-354.

NishidA T. 1979. The social structure of chimpanzees of the Mahali mountains, pp. 73121. In: Hamburg D.A. \& Mcgown E.R., Edits. The Great Apes: Perspecting on human evolution. Menlo Park: Benjamin \& Cummings.

NIsHIDA T. 1990. The chimpanzees of the Mahale mountains. Tokyo: University of Tokyo Press.

Nishida T., Corp N., Hamai M., Hasegawa T., Hiraiwa-Hasegawa M., HosaKa K., Hunt K.D., Itoh N., Kawanaka K., Matsumoto-Oda A., Mitani J.C., Nakamura M., Norikoshi K., Sakamaki T., Turner L., Uehara S. \& Zamma K. 2003. Demography, female life history, and reproductive profiles among the chimpanzees of Mahale. American Journal of Primatology 59 (3): 99-121.

Nishida T. \& Uehara S. 1983. Natural diet of chimpanzees (Pan troglodytes schweinsfurthii): long-term record from the Mahale Moutains, Tanzania. African Study Monographs 3: 109-130.

NishinaRA T. 1995. Feeding Ecology of Western Lowland Gorillas in the Nouabale-Ndoki National-Park, Congo. Primates 36: 151-168.

Remis M. 1995. Effects of body size and social context on the arboreal activities of lowland gorillas in the Central African Republic. American Journal of Physical Anthropology 97: 413-433.

REMIS M.J. 1997. Ranging and grouping patterns of a western lowland gorilla group at Bai Hokou, Central African Republic. American Journal of Primatology 43: 111-133.

Remis M.J., Dierenfeld E.S., Mowry C.B. \& Carroll R.W. 2001. Nutritional aspects of western lowland gorilla (Gorilla gorilla gorilla) diet during seasons of fruit scarcity at Bai Hokou, Central African Republic. International Journal of Primatology 22: 807-839.

Reynolds V. \& Reynolds F. 1965. Chimpanzees of the Budongo Forest. New York: Holt, Rinehart and Winston.

RoBbins M.M. 1999. Male mating patterns in wild multimale mountain gorilla groups. Animal Behaviour 57: 1013-1020.

SABATER PI J. 1977. Contribution to the study of alimentation of lowland gorillas in the natural state, in Rio Muni, Republic of Equatorial Guinea (West Africa). Primates 18: $183-204$.

SABATER Pi J. 1979. Feeding behavior and diet of chimpanzees (Pan troglodytes troglodytes) in the Okorobiko Mountains of Rio-Muni (West- Africa). Zeitschrift für Tierpsychologie (Journal of Comparative Ethology) 50: 265-281.

SAKURA O. 1994. Factors affecting party size and composition of chimpanzees (Pan troglodytes verus) at Bossou, Guinea. International Journal of Primatology 15: 167-183.

Schaller G.B. 1963. The Mountain Gorilla: Ecology and Behavior. Chicago: The University of Chicago Press.

Stokes E.J., PaRnell R.J. \& OleJNiczaK C. 2003. Female dispersal and reproductive success in wild western lowland gorillas (Gorilla gorilla gorilla). Behavioral Ecology and Sociobiology 54: 329-339.

SugIYAma Y. \& Koman J. 1987. A preliminary list of chimpanzee alimentation at Bossou, Guinea. Primates 28: 133-147.

Tакемото H. 2004. Seasonal change in terrestriality of chimpanzees in relation to microclimate in the tropical forest. American Journal of Physical Anthropology 124: 81-92.

Tutin C.E.G., McGrew W.C. \& BALDwin P.J. 1983. Social organization of savanna-dwelling chimpanzees, Pan troglodytes verus, at Mt. Assirik, Senegal. Primates 24: 154-173.

Tweheyo M., Lye K.A. \& Weladji R.B. 2004. Chimpanzee diet and habitat selection in the Budongo Forest Reserve, Uganda. Forest Ecology and Management 188: 267-278.

UNEP-WCPA World database on protected areas. (http://www.unep-wcmc.org/wdpa/). 
UNGAR P. 2004. Dental topography and diets of Australopithecus afarensis and early Homo. Journal of Human Evolution 46: 605-622.

WATTS D. 1988. Environmental influences on mountain gorilla time budgets. American Journal of Primatology 15: 195-211.

WATTS D.P. 1984. Composition and variability of mountain gorilla diets in the central Virungas. American Journal of Primatology 7: 323-356.

WatTs D.P. 1991. Strategies of habitat use by mountain gorillas. Folia Primatologica 56: $1-16$.

WATTS D.P. 1998. Long-term habitat use by mountain gorillas (Gorilla gorilla beringei). 1. Consistency, variation, and home range size and stability. International Journal of Primatology 19: 651-679.

WatTs D.P. 2000. Grooming between male chimpanzees at Ngogo, Kibale National Park. I. Partner number and diversity and grooming reciprocity. International Journal of Primatology 21: 189-210.

WHITE F.J. 1992. Activity budgets, feeding behavior, and habitat use of pygmy chimpanzees at Lomako, Zaire. American Journal of Primatology 26: 215-223.

White F.J. 1996. Comparative socio-ecology of Pan paniscus, pp. 29-44. In: Mcgrew W.C. et al., Edits. Great Ape societies. Cambridge: Cambridge University Press.

Williamson D. \& DunBar R.I.M. 1999. Energetics, time budgets and group size, pp. 320338. In: Lee P.C., Edit. Comparative primate socioecology. Cambridge: Cambridge University Press.

Willmott C.J. \& Feddema J.J. 1992. A more rational climatic moisture index. Professional Geographer 44: 84-88.

Willmott C.J. \& MatsuURA K. 2001. Terrestrial air temperature and precipitation: monthly and annual climatologies (Version 3.02) http://climate.geog.udel.edu/ climate/.

Wrangham R.W. 1974. Artifical feeding of chimpanzees and baboon in their natural habitat. Animal Behaviour 22: 83-93.

WRANGHAm R.W. 1975. The behavioral ecology of chimpanzees in Gombe National Park, Tanzania. PhD Thesis, Cambridge University.

Wrangham R.W. 1977. Feeding behaviour of chimpanzees in Gombe National Park, Tanzania, pp. 503-538. In: Clutton-Brock T.H., Edit. Primate Ecology. London: London Academic Press.

WRANGHAM R.W. 1986. Ecology and social relationships in two species of chimpanzees, pp. 352-378. In: Rubenstein D.I. \& Wrangham R.W., Edits. Ecology and social evolution: Birds and mammals. Princeton, NJ: Princeton University Press.

Wrangham R.W. 2000. Why are male chimpanzees more gregarious than mothers? A scramble competition hypothesis, pp. 248-258. In: Kappeler P., Edit. Males Primate. Cambridge: Cambridge University Press.

Wrangham R.W., Clark A.P. \& Isabirye-Basuta G. 1992. Female social relationships and social organisation of the Kibale Forest chimpanzees, pp. 81-98. In: Nishida T. et al., Edits. Topics in primatology. Tokyo: University of Tokyo Press.

Wrangham R.W. \& SMUts B.B. 1980. Sex differences in the behavioural ecology of chimpanzees in the Gombe National Park, Tanzania. Journal of Reproduction and Fertility (Suppl.) 28: 13-31.

YAMAGIWA J. 1999. Socioecological factors influencing population structure of gorillas and chimpanzees. Primates 40: 87-104.

YAMAgiWA J. \& KAHEKWA J. 2001. Dispersal patterns, group structure, and reproductive parameters of eastern lowland gorillas at Kahuzi in the absence of infanticide, pp. 89-122. In: Robbins M. et al., Edits. Mountain gorillas: Three decades of research in Karisoke. New York: Cambridge University Press.

Yamagiwa J., KaheKwa J. \& Basabose A.K. 2003. Intra-specific variation in social organization of gorillas: implications for their social evolution. Primates 44: 359-369. 
Yamagiwa J., Maruhashi T., Yumoto T. \& Mwana N. 1996. Dietary and ranging overlap in sympatric gorillas and chimpanzees in Kahuzi-Biega National Park, Zaire. Cambridge: Cambridge University Press.

YAmagiwa J. \& Mwanza N. 1994. Day journey length and daily diet of solitary male gorillas in lowland and highland habitats. International Journal of Primatology 15: 207-224.

Yamagiwa J., Mwanza N., Yumoto T. \& Maruhashi T. 1992. Travel distances and food habits of eastern lowland gorillas: a comparative analysis, pp. 267-281. In: Itoigawa N. et al., Edits. Topics in primatology, Vol. 2: Behavior, Ecology and Conservation. University of Tokyo Press.

YAмакоsнi G. 1998. Dietary responses to fruit scarcity of wild chimpanzees in Bossou, Guinea: Possible implications for ecological importance of tool use. American Journal of Physical Anthropology 106: 283-295.

Yamakoshi G. 2004. Food seasonality and socioecology in Pan: Are West African chimpanzees another bonobo? African Study Monographs 25: 45-60. 